\title{
Preface for the special issue on robotics in smart manufacturing
}

\author{
Pedro Neto • A. Paulo Moreira
}

Received: 28 April 2014 / Accepted: 2 May 2014 / Published online: 10 June 2014

(C) Springer-Verlag London 2014

Today, perhaps more than ever, manufacturing industry is seen by society as a major means of generating economic growth and jobs creation. In the current context of the global market, manufacturing companies need to be competitive to survive, i.e., produce more, better, cheaper, and customer-oriented. At the same time, these companies, usually small- and mediumsized enterprises (SMEs), have to be flexible to react to market demands in appropriate time.

Industrial robots are key elements in flexible manufacturing as they can be programmed and re-programmed to perform different tasks in different environments. However, it is not easy to interact with robots and integrate them in manufacturing cells. Robot programming is still a non-intuitive task that requires technical skills in robot programming and in the manufacturing process being applied. Nevertheless, industrial robots are increasingly being used in diverse traditional and non-traditional manufacturing processes. In fact, recent advances in human-robot interaction, robot autonomy, humanrobot co-working, and robot-robot interaction have led to the emergence of more and more robots operating in autonomous and smart manufacturing systems. These are not created by decree or with the purpose of recreating science fiction. On the contrary, they emerged due to the global market demands for cheaper, diversified, and better-quality products.

This special issue of The International Journal of Advanced Manufacturing Technology (IJAMT) contains revised and extended versions of selected papers presented at the Workshop on Robotics in Smart Manufacturing (WRSM) organized under the umbrella of the 23rd International Conference on Flexible Automation and Intelligent Manufacturing, FAIM 2013, which was

P. Neto $(\bowtie) \cdot$ A. P. Moreira

Department of Mechanical Engineering, University of Coimbra, Polo

II, 3030-788 Coimbra, Portugal

e-mail: pedro.neto@dem.uc.pt held in Porto, Portugal. The workshop attracted 29 paper submissions, and 20 papers were accepted for presentation (69\% acceptance rate). Contributions were mainly received not only from European countries but also from the People's Republic of China, Canada, Algeria, and Brazil. In summary, the WRSM was an international forum that brings together practitioners and researchers to present recent developments and identify possible directions for further research in the field. The workshop included presentations on diverse issues related to the interdisciplinary field of industrial robotics, all of them describing the application of robots in manufacturing processes. This special issue contains extended versions of the seven papers with the highest reviewer ratings. All papers present both theoretical and applicationoriented contributions. In addition, each paper is complemented with a demonstration video showing the achieved results. Some papers report tangible results arising from flagship European research projects. The selected papers address the following subjects:

- Robotic machining;

- Robot-assisted manufacturing of carbon fiber reinforced plastics (CFRP) for the aerospace industry;

- Robotic systems for large workspace applications;

- Robotic friction stir welding;

- Robotic deburring of aerospace components;

- Robotic coating and spray painting by means of programming by demonstration;

- Robots for flexible grasping and packaging.

Finally, the editors would like to thank to all the 16 members of the scientific committee, the 37 reviewers, authors, attendees, FAIM organization staff, sponsors, and to everyone who contributed to make the WRSM a success. Special thanks go to the editor Professor Kai Cheng for this opportunity to prepare this special issue. 